\title{
Dampness, mould, onset and remission of adult respiratory symptoms, asthma and rhinitis
}

\author{
Juan Wang ${ }^{1,11}$, Mihkel Pindus ${ }^{2,11}$, Christer Janson ${ }^{3}$, Torben Sigsgaard ${ }^{4}$, \\ Jeong-Lim Kim ${ }^{5}$, Mathias Holm ${ }^{5}$, Johan Sommar ${ }^{6}$, Hans Orru 2,6, \\ Thorarinn Gislason ${ }^{7}$, Ane Johannessen ${ }^{8,9}$, Randi J. Bertelsen $8,9,10$ and \\ Dan Norbäck ${ }^{1}$
}

Affiliations: ${ }^{1}$ Dept of Medical Sciences, Occupational and Environmental Medicine, Uppsala University, Uppsala, Sweden. ${ }^{2}$ Institute of Family Medicine and Public Health, University of Tartu, Tartu, Estonia. ${ }^{3}$ Dept of Medical Sciences, Respiratory, Allergy and Sleep Research, Uppsala University, Uppsala, Sweden. ${ }^{4}$ Dept of Public Health, Section for Environment, Occupation and Health, Aarhus University, Danish Ramazzini Centre, Aarhus, Denmark. ${ }^{5}$ Occupational and Environmental Medicine, Gothenburg University, Gothenburg. Sweden. ${ }^{6}$ Occupational and Environmental Medicine, Dept of Public Health and Clinical Medicine, Umeå University, Umeå, Sweden. ${ }^{7}$ Landspitali University Hospital (E7), Reykjavik, Iceland. ${ }^{8}$ Centre for International Health, Dept of Global Public Health and Primary Care, University of Bergen, Bergen, Norway. ${ }^{9}$ Dept of Occupational Medicine, Haukeland University Hospital, Bergen, Norway. ${ }^{10}$ Dept of Clinical Science, University of Bergen, Bergen, Norway. ${ }^{11}$ These authors contributed equally to this work.

Correspondence: Juan Wang, Dept of Medical Sciences, Occupational and Environmental Medicine, Uppsala University, SE-751 85 Uppsala, Sweden. E-mail: juan.wangdamedsci.uu.se

@ERSpublications

Dampness and mould at home and in the workplace can increase onset and decrease remission of respiratory symptoms, doctor-diagnosed asthma and rhinitis among adults. Our study adds new evidence on the health significance of dampness and mould. http://ow.ly/Ek1330o3IBn

Cite this article as: Wang J, Pindus M, Janson C, et al. Dampness, mould, onset and remission of adult respiratory symptoms, asthma and rhinitis. Eur Respir J 2019; 53: 1801921 [https://doi.org/10.1183/ 13993003.01921-2018].

\section{ABSTRACT}

Study question: Is dampness and indoor mould associated with onset and remission of respiratory symptoms, asthma and rhinitis among adults?

Materials and methods: Associations between dampness, mould and mould odour at home and at work and respiratory health were investigated in a cohort of 11506 adults from Iceland, Norway, Sweden, Denmark and Estonia. They answered a questionnaire at baseline and 10 years later, with questions on respiratory health, home and work environment.

Results: Baseline water damage, floor dampness, mould and mould odour at home were associated with onset of respiratory symptoms and asthma (OR 1.23-2.24). Dampness at home during follow-up was associated with onset of respiratory symptoms, asthma and rhinitis (OR 1.21-1.52). Dampness at work during follow-up was associated with onset of respiratory symptoms, asthma and rhinitis (OR 1.31-1.50). Combined dampness at home and at work increased the risk of onset of respiratory symptoms and rhinitis. Dampness and mould at home and at work decreased remission of respiratory symptoms and rhinitis. The answer to the question: Dampness and mould at home and at work can increase onset of respiratory symptoms, asthma and rhinitis, and decrease remission. 


\section{Introduction}

Respiratory illnesses can be affected by the home environment [1-4]. Indoor dampness and mould are associated with respiratory illnesses, but most studies are cross-sectional studies which limits conclusions on causality [1-4]. One review included 16 studies on associations between residential dampness and mould and incidence of asthma [1], concluding that dampness and mould at home are determinants of incident asthma. However, only two studies investigated adult asthma $[5,6]$. Later, a longitudinal multicentre study in Europe demonstrated that water damage and indoor moulds in homes were related to asthma onset [7].

Asthma and rhinitis coexist [8,9]. An association between adult asthma and allergic rhinitis has been documented in a population study in Sweden [10]. A systematic review concluded that dampness and mould was associated with rhinitis [2], but only two out of 31 studies were on adult rhinitis [11, 12]. None were prospective studies.

Few studies exist on asthma or rhinitis in relation to dampness at work. Working in a damp office building was associated with work-related asthma [13]. An incident case-control study found that mould and mould odour in the workplace were related to adult-onset asthma $[6,14]$. One hospital study showed that water damage was associated with onset of asthma [15]. An intervention study found that remediation of mould in an office building decreased asthmatic symptoms [16].

Mould odour at home has been shown to be associated with incident asthma [1]. As compared to other dampness indicators, mould odour had the strongest association with asthma onset [1] and rhinitis [2].

More longitudinal studies are needed on respiratory effects of dampness and mould. The Respiratory Health in Northern Europe (RHINE) study is a large population-based cohort study among adults [5]. Our aim was to study associations between onset and remission of respiratory symptoms, asthma and rhinitis among adults and indoor dampness, mould and mould odour at home and in the workplace building, in a RHINE follow-up from 1999-2000 (baseline) to 2010-2012 (follow-up).

\section{Materials and methods}

\section{Study design and target population}

The RHINE II study is a follow-up study of subjects from seven Nordic study centres from the European Community Respiratory Health Survey stage (ECRHS) I in 1989-1992. In ECRHS I, 3000-4000 subjects (aged 20-44 years) were randomly selected from the population register in each centre. A postal questionnaire was then sent to those subjects.

The RHINE II study included all subjects from seven centres in northern Europe: Reykjavik in Iceland, Bergen in Norway, Umeå, Uppsala and Göteborg in Sweden, Aarhus in Denmark and Tartu in Estonia. In total, 21681 subjects participated in ECRHS I (response rate 86\%) [17]. In RHINE II, participants received a follow-up postal questionnaire in 1999-2000. The RHINE II questionnaire included questions on respiratory health and the indoor environment at home and at work. The RHINE II participants were invited for a second follow-up (RHINE III) in 2010-2012, with identical questions on respiratory health as in RHINE II. In total, 11506 subjects participated in RHINE II and RHINE III (response rate 71\%) (figure 1). Participation was defined as answering at least one of five questions on respiratory symptoms (wheeze, nocturnal chest tightness, nocturnal attacks of breathlessness, nocturnal cough or asthma attack; detailed description is given later). In the present study, we define RHINE II as the baseline study and the RHINE III survey as the follow-up.

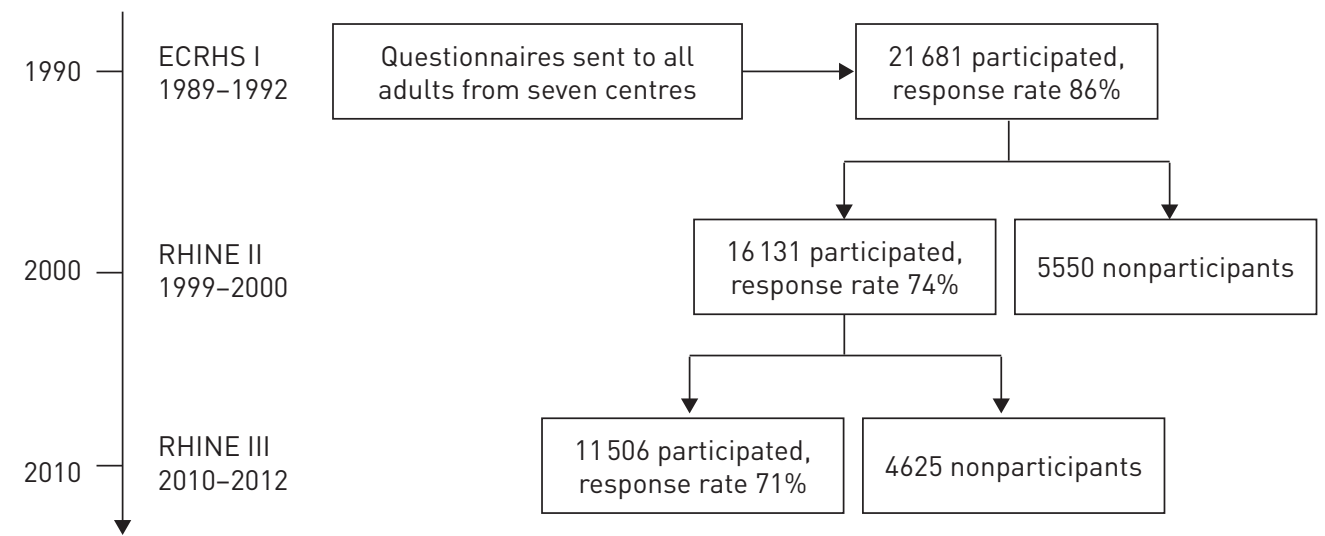

FIGURE 1 The flow chart of the study design. ECRHS: European Community Respiratory Health Survey; RHINE: Respiratory Health in Northern Europe study. 
Assessment of health and demographic data

Questions regarding respiratory symptoms (same at baseline and follow-up) included the following:

1) Wheezing or whistling in the chest in the last 12 months ("wheeze")

2) Woken up with a feeling of tightness in the chest at any time in the last 12 months ("nocturnal chest tightness")

3) Woken up by an attack of shortness of breath in the last 12 months ("nocturnal attacks of breathlessness")

4) Woken up by an attack of coughing in the last 12 months ("nocturnal cough")

5) An asthma attack in the last 12 months ("asthma attack")

6) Usually bring up phlegm or have any problem with bringing up phlegm in the past 12 months ("productive cough")

7) Currently taking any medication (including inhalers, aerosols or tablets) for asthma

Current asthma was defined as having either asthma attacks in the past 12 months or current asthma medication, or both [18].

There was one question regarding doctor-diagnosed asthma:

1) Ever had asthma diagnosed by a doctor ("ever doctor-diagnosed asthma"). This question measured cumulative incidence.

Questions regarding allergic rhinitis and rhinitis symptoms included the following:

1) Any nasal allergies including hay fever ("allergic rhinitis")

2) Ever had nose symptoms such as stuffy nose, runny nose and/or sneezing when not having a cold ("ever rhinitis symptoms"). This question measured cumulative incidence of rhinitis

Onset of doctor-diagnosed asthma, allergic rhinitis and rhinitis symptoms were defined as not reporting the particular respiratory illness at baseline, but reporting it at follow-up.

Onset of a particular respiratory symptom such as wheeze, nocturnal chest tightness, nocturnal breathlessness, nocturnal cough, productive cough or current asthma was defined as not reporting the particular symptom at baseline, but reporting the particular symptom at follow-up [5]. Participants with doctor-diagnosed asthma at baseline were excluded when calculating onset of these respiratory symptoms.

Remission of a particular respiratory symptom (wheeze, nocturnal chest tightness, nocturnal breathlessness, nocturnal cough, productive cough and current asthma) was defined as reporting the particular symptom at baseline, but not at follow-up, including those with doctor-diagnosed asthma at baseline.

Remission of allergic rhinitis was defined as reporting allergic rhinitis at baseline, but not at follow-up.

Data on sex, age, height and weight were obtained from the baseline data, while education level was only available at follow-up. Smoking habit (never-/ever-/current smokers) were available both at baseline and follow-up. Body mass index (BMI) was calculated as the ratio of weight in kilograms to height in metres squared $\left(\mathrm{kg} \cdot \mathrm{m}^{-2}\right)$. Change of smoking habit from baseline to follow-up (no change/start smoking/stop smoking) was calculated. Education level was categorised as primary school, high school or university education at follow-up.

\section{Assessment of indoor dampness, mould and mould odour}

Four questions about the home environment were asked about the current home in the past 12 months, as follows:

1) Water leakage or water damage indoors on walls, floors or ceilings ("water damage")

2) Bubbles or yellow discolouration on plastic floor covering or black discolouration of parquet floor ("floor dampness")

3) Visible mould growth indoors on walls, floors or ceilings ("visible mould")

4) Mould odour in one or several rooms (other than the cellar)

The variable "any dampness" was defined as answering yes to question 1), 2) or 3) above.

Moreover, two questions were asked about home and workplace exposure during the follow-up period:

1) Any dampness damage, water leakage or visible mould at home during the past 10 years ("dampness or mould at home during follow-up")

2) Any dampness damage, water leakage or visible mound in the workplace building during the past 10 years ("dampness or mould at work during follow-up") 
A categorised variable with four alternatives was created: no dampness/mould; dampness/mould at home only; dampness/mould at work only; and dampness/mould at home and at work.

\section{Statistical analysis}

We used Stata 15.1 (Stata Corporation, College Station, TX, USA). Two-level (centre, individual) logistic regression models were performed to estimate associations between dampness indicators at baseline or during follow-up and onset of respiratory symptoms (wheeze, nocturnal chest tightness, nocturnal breathlessness, nocturnal cough, productive cough and current asthma), doctor-diagnosed asthma, allergic rhinitis and rhinitis symptoms, adjusting for sex, age, smoking habit at baseline, change of smoking habit from baseline to follow-up, BMI at baseline and education level at follow-up. Subjects with doctor-diagnosed asthma at baseline were excluded when analysing onset of respiratory symptoms. Similar two-level logistic regression models were then applied to estimate associations between dampness indicators and remission of respiratory symptoms and allergic rhinitis. Additionally, associations between combination of dampness and mould at home and at work during follow-up (categorised as none, at home, at work or both) and onset of respiratory symptoms and allergic rhinitis were estimated using similar logistic regression models. Associations were expressed as OR (95\% CI), with 5\% significance.

\section{Ethics statement}

This study was conducted with the approval of the appropriate ethics board at each centre. All participants gave informed consent prior to participation.

\section{Results}

In total, 11506 respondents were included; $54.3 \%$ were female, $26.3 \%$ were current smokers and $26.4 \%$ were ex-smokers at baseline. During follow-up, $2.4 \%$ started smoking and $12.1 \%$ stopped smoking. There were no associations between smoking habit and dampness indicators at baseline (RHINE II). The mean \pm SD age at baseline was $40 \pm 7.3$ years. The mean follow-up time was $11.3 \pm 1.1$ years. Nonparticipants in RHINE II had slightly higher prevalence of wheeze, nocturnal chest tightness and nocturnal attacks of breathlessness, but lower prevalence of allergic rhinitis in ECRHS I as compared to participants (data not shown). Moreover, nonparticipants in RHINE III had slightly higher prevalence of respiratory symptoms and asthma in RHINE II as compared to participants (table 1). However, prevalence of dampness indicators at home at baseline (RHINE II) did not differ between participants and nonparticipants in RHINE III (table 1).

TABLE 1 Respiratory health and dampness indicators in the Respiratory Health in Northern Europe (RHINE) II study among participants and nonparticipants in RHINE III

Participants in RHINE III Nonparticipants in RHINE III p-value

\begin{tabular}{lccc}
\hline Subjects $\mathbf{n}$ & 11506 & 4625 & \\
Health RHINE II & & & $<0.001$ \\
Wheeze & 19.4 & 23.6 & $<0.001$ \\
Nocturnal chest tightness & 10.6 & 12.8 & $<0.001$ \\
Nocturnal attacks of breathlessness & 4.7 & 6.7 & 0.002 \\
Nocturnal cough & 28.3 & 30.8 & $<0.001$ \\
Productive cough & 16.6 & 21.1 & 0.022 \\
Current asthma\# & 6.5 & 7.5 & 0.010 \\
Ever doctor-diagnosed asthma & 7.9 & 9.1 & 0.525 \\
Allergic rhinitis & 23.3 & 22.9 & 0.265 \\
Ever rhinitis symptoms & 47.9 & 48.9 & 0.713 \\
Dampness RHINE II & 13.4 & 13.6 & 0.862 \\
Water damage & 3.8 & 3.8 & 0.963 \\
Floor dampness & 6.7 & 6.7 & 0.349 \\
Visible mould & 3.5 & 3.8 & 0.685 \\
Mould odour & 17.9 & 18.1 & \\
Any dampness & & & \\
\end{tabular}

Data are presented as (\%), unless otherwise stated. " : defined as an asthma attack in the past 12 months, current asthma medication or both; ": defined as water damage, floor dampness or visible mould in the past 12 months at baseline. 
TABLE 2 Onset and remission over the study period of respiratory symptoms, asthma, allergic rhinitis and rhinitis symptoms

\begin{tabular}{|c|c|c|c|c|c|c|c|c|}
\hline & Aarhus & Reykjavik & Bergen & Göteborg & Umeå & Uppsala & Tartu & Total \\
\hline \multicolumn{9}{|l|}{ Onset } \\
\hline Wheeze & 8.7 & 13.0 & 9.4 & 9.5 & 7.7 & 8.8 & 13.7 & 9.9 \\
\hline Nocturnal attacks of breathlessness & 2.4 & 2.2 & 3.8 & 2.9 & 3.1 & 2.9 & 11.0 & 3.7 \\
\hline Nocturnal cough & 13.4 & 16.6 & 12.3 & 17.5 & 18.4 & 16.7 & 31.5 & 17.0 \\
\hline Productive cough & 6.6 & 12.0 & 9.0 & 9.8 & 9.7 & 7.5 & 12.6 & 9.3 \\
\hline Current asthma & 2.6 & 6.3 & 4.8 & 3.7 & 3.3 & 4.7 & 3.6 & 4.1 \\
\hline Allergic rhinitis & 11.2 & 12.7 & 7.8 & 7.3 & 7.1 & 7.5 & 14.4 & 9.5 \\
\hline Ever rhinitis symptoms & 25.2 & 27.6 & 24.8 & 24.4 & 22.0 & 22.1 & 40.9 & 25.9 \\
\hline \multicolumn{9}{|l|}{ Remission } \\
\hline Wheeze & 54.8 & 44.9 & 45.7 & 46.2 & 47.4 & 51.0 & 41.0 & 47.5 \\
\hline Nocturnal chest tightness & 72.4 & 73.4 & 63.0 & 71.3 & 66.7 & 69.0 & 56.1 & 66.9 \\
\hline Nocturnal attacks of breathlessness & 70.9 & 76.7 & 66.2 & 66.3 & 71.3 & 61.9 & 57.3 & 65.8 \\
\hline Nocturnal cough & 61.5 & 49.8 & 52.6 & 47.2 & 44.3 & 46.7 & 32.2 & 48.2 \\
\hline
\end{tabular}

Data are presented as (\%). " : defined as an asthma attack in the past 12 months, current asthma medication or both.

The highest onset rate over the study period was for rhinitis symptoms (25.9\%). Onset rates of wheeze (9.9\%), productive cough $(9.3 \%)$ and allergic rhinitis $(9.5 \%)$ were similar. The onset rate for doctor-diagnosed asthma was $4.3 \%$. Among all the centres, Tartu had the highest onset rates for most respiratory symptoms. Approximately half of the participants with wheeze, nocturnal cough or productive cough at baseline were free from having those particular symptoms at follow-up. The highest remission rate was for nocturnal chest tightness (66.9\%) (table 2).

Among environmental factors reported at baseline, water damage (13.4\%) and visible mould (6.7\%) were most common (table 3). A quarter (25.2\%) of the participants in follow-up reported dampness at home in their current or previous home during the past 10 years, and $19.4 \%$ reported dampness in their current or previous workplace building in the past 10 years. All signs of indoor dampness, except floor dampness, were most common in Tartu. Floor dampness was most common in Reykjavik. Mould odour was most common in Tartu. In general, the signs of indoor dampness and mould were less common in Bergen, Göteborg and Umeå.

Dampness indicators at baseline and during follow-up were risk factors for onset of wheeze, nocturnal chest tightness, nocturnal breathlessness, nocturnal cough, productive cough, current asthma or doctor-diagnosed

\begin{tabular}{|c|c|c|c|c|c|c|c|c|}
\hline & Aarhus & Reykjavik & Bergen & Göteborg & Umeå & Uppsala & Tartu & Total \\
\hline \multicolumn{9}{|l|}{ Baseline (at home) } \\
\hline Water damage & 13.3 & 20.0 & 13.3 & 8.1 & 10.0 & 8.9 & 23.3 & 13.4 \\
\hline Floor dampness & 1.6 & 6.7 & 2.1 & 4.2 & 5.7 & 3.9 & 2.9 & 3.8 \\
\hline Visible mould & 9.8 & 6.1 & 4.7 & 4.6 & 3.9 & 6.4 & 13.0 & 6.7 \\
\hline Mould odour & 4.2 & 4.8 & 2.3 & 2.4 & 2.5 & 3.2 & 5.9 & 3.6 \\
\hline Any dampness ${ }^{\#}$ & 17.8 & 22.7 & 16.2 & 12.4 & 14.0 & 14.9 & 31.7 & 17.9 \\
\hline \multicolumn{9}{|l|}{ Follow-up } \\
\hline $\begin{array}{l}\text { Dampness or mould at } \\
\text { home during follow-up }\end{array}$ & 23.8 & 32.6 & 24.5 & 20.9 & 20.9 & 23.2 & 34.2 & 25.2 \\
\hline $\begin{array}{l}\text { Dampness or mould in } \\
\text { the workplace building } \\
\text { during follow-up }\end{array}$ & 11.6 & 22.1 & 17.1 & 19.4 & 21.0 & 23.5 & 23.7 & 19.4 \\
\hline
\end{tabular}

Data are presented as (\%). " : defined as water damage, floor dampness or visible mould in the past 12 months at baseline. 
asthma (table 4). Mould odour at baseline was associated with onset of wheeze, nocturnal chest tightness, nocturnal breathlessness, nocturnal cough and doctor-diagnosed asthma (table 4).

There were few associations between dampness indicators and rhinitis. Dampness or mould at home during follow-up was the only risk factor for onset of allergic rhinitis. Dampness or mould at home during follow-up and dampness or mould at work during follow-up were both associated with onset of rhinitis symptoms (table 4).

Dampness and indoor mould decreased the remission rate. Water damage at baseline was related to less remission of nocturnal chest tightness and nocturnal cough at follow-up. Visible mould at baseline was associated with less remission of nocturnal chest tightness and nocturnal breathlessness. Any dampness at baseline decreased the likelihood for remission of nocturnal chest tightness, nocturnal breathlessness and productive cough. Dampness or mould at home during follow-up was related to decreased remission of nocturnal cough and allergic rhinitis. Dampness or mould at work during follow-up was associated with decreased remission of wheeze (table 5).

Participants exposed to dampness both at home and in workplace buildings had the strongest associations with onset of wheeze, nocturnal chest tightness, nocturnal breathlessness, nocturnal cough, productive cough, doctor-diagnosed asthma and rhinitis symptoms (table 6).

\section{Discussion}

In this prospective study we found associations between dampness and mould at home at baseline and onset of respiratory symptoms and doctor-diagnosed asthma. Moreover, dampness and mould decreased the remission of respiratory symptoms and allergic rhinitis. Moreover, mould odour at home at baseline was associated with onset of respiratory symptoms and doctor-diagnosed asthma. Dampness or mould at home and at work during follow-up were related to onset of respiratory symptoms and doctor-diagnosed asthma as well as allergic rhinitis and rhinitis symptoms. Exposure to dampness during follow-up both at home and at work increased the risk of onset of respiratory symptoms and rhinitis symptoms.

In total, $17.9 \%$ of the homes had dampness at baseline (in the past 12 months). This prevalence is similar to that reported in a previous review (16.5\%) including 31 studies on dampness and mould in the European housing stock [19]. Water damage (in the past 12 months) at baseline was $13.4 \%$ in our study. This is higher than the mean prevalence of water damage $(10.0 \%)$ in Europe reported from the ECRHS study [20]. In our study, the prevalence of water damage differed from $7.7 \%$ in Göteborg to $23.4 \%$ in Tartu, possibly due to different building technologies in different Nordic countries. It has been reported that dampness in homes in Europe is associated with annual precipitation and higher ambient temperature [20]. Thus, differences in climate between the centres may also play role for the differences in prevalence of dampness. However, the prevalence of visible mould in our study $(6.7 \%)$ was much lower as compared to the multicentre study (16\%) [20].

Participants with doctor-diagnosed asthma at baseline were excluded from the calculation of onset of respiratory symptoms, since the aim was to study onset of symptoms, and not worsening of existing asthma. The associations between dampness at home and onset of respiratory symptoms and asthma in our study is consistent with two previous studies [5, 7]. Dampness at home increased onset of respiratory symptoms in the RHINE II study [5], with slightly lower odds ratios as compared to our study. The other multicentre study in Europe found stronger associations between water damage (OR 1.46), visible mould (OR 1.30) and onset of asthma than our study. Dampness problems on floors have been reported to cause higher emission of ammonia [21] and 2-etyl-1-hexanol to indoor air [22]. Previous prevalence studies reported that dampness in the floor construction can be associated with reduced lung function (forced expiratory volume in $1 \mathrm{~s}$ ) [23, 24], asthma symptoms [5, 23-25] and asthma [26].

Our study suggested that mould odour at baseline can increase onset of respiratory symptoms and doctor-diagnosed asthma. This is in agreement with a previous review on incident asthma [1]. However, this review included mainly childhood studies [1]. Previous prevalence studies have shown associations between mould odour at home and asthma or asthmatic symptoms among adults [11, 27]. Mould odour can be enhanced by poor ventilation. One Swedish study found that mould odour at home was associated with asthma symptoms in the initial model, but the association disappeared when adjusting for measured air exchange ventilation in the home [25]. An experimental study found that increased ventilation was associated with fewer reports of odour in university classrooms [28]. Unfortunately, we have no information on ventilation flow in the RHINE study.

We found that dampness and mould in the workplace building during follow-up was associated with onset of respiratory symptoms and doctor-diagnosed asthma. This is in agreement with previous studies on respiratory effects of dampness in workplace buildings. One recent review concluded that exposure to mould 
TABLE 4 Adjusted odds ratios with $95 \%$ confidence intervals for onset of respiratory symptoms, doctor-diagnosed asthma and rhinitis

Water damage Floor dampness Visible mould Mould odour Any dampness ${ }^{\#} \quad$ Dampness or mould

at home during follow-up

Dampness or mould

at home during follow-up

\begin{tabular}{|c|c|c|c|c|c|c|c|}
\hline Wheeze & $1.60(1.31-1.97)$ & $2.24(1.61-3.13)$ & $1.49(1.12-1.98)$ & $1.56(1.07-2.29)$ & $1.61(1.33-1.94)$ & $1.38(1.17-1.64)$ & $1.46(1.21-1.75)$ \\
\hline $\mathrm{p}$-value & $<0.001$ & $<0.001$ & 0.006 & 0.022 & $<0.001$ & $<0.001$ & $<0.001$ \\
\hline Nocturnal chest tightness & $1.28(1.02-1.60)$ & $1.61(1.08-22.39)$ & $1.21(0.88-1.66)$ & $1.81(1.25-2.63)$ & $1.28(1.04-1.58)$ & $1.34(1.11-1.61)$ & $1.50(1.22-1.83)$ \\
\hline p-value & 0.035 & 0.018 & 0.247 & 0.002 & 0.018 & 0.002 & $<0.001$ \\
\hline Nocturnal breathlessness & $1.32(0.98-1.79)$ & $2.11(1.32-3.38)$ & $1.43(0.96-2.12)$ & $2.01(1.26-3.22)$ & $1.48(1.13-1.93)$ & $1.24(0.97-1.60)$ & $1.41(1.08-1.84)$ \\
\hline p-value & 0.069 & 0.002 & 0.075 & 0.004 & 0.004 & 0.088 & 0.012 \\
\hline Nocturnal cough & $1.23(1.02-1.49)$ & $1.51(1.08-2.11)$ & $1.34(1.03-1.73)$ & $1.46(1.04-2.06)$ & $1.31(1.11-1.55)$ & $1.21(1.04-1.40)$ & $1.47(1.25-1.72)$ \\
\hline p-value & 0.032 & 0.015 & 0.029 & 0.030 & 0.002 & 0.013 & $<0.001$ \\
\hline Productive cough & $1.21(0.97-1.51)$ & $1.48(1.02-2.14)$ & $1.46(1.10-1.95)$ & $1.37(0.92-2.04)$ & $1.35(1.12-1.65)$ & $1.52(1.29-1.81)$ & $1.33(1.11-1.61)$ \\
\hline p-value & 0.088 & 0.038 & 0.010 & 0.116 & 0.002 & $<0.001$ & 0.003 \\
\hline Current asthma & $1.34(1.01-1.77)$ & $1.44(0.90-2.31)$ & $1.25(0.84-1.86)$ & $1.46(0.89-2.39)$ & $1.36(1.05-1.76)$ & $1.09(0.86-1.38)$ & $1.25(0.97-1.61)$ \\
\hline p-value & 0.044 & 0.129 & 0.279 & 0.136 & 0.018 & 0.482 & 0.084 \\
\hline Doctor-diagnosed asthma & $1.36(1.04-1.78)$ & $1.96(1.30-2.96)$ & $1.36(0.93-1.97)$ & $2.23(1.48-3.37)$ & $1.43(1.12-1.83)$ & $1.32(1.06-1.65)$ & $1.40(1.10-1.79)$ \\
\hline p-value & 0.027 & 0.001 & 0.109 & $<0.001$ & 0.004 & 0.014 & 0.006 \\
\hline Allergic rhinitis & $1.14(0.92-1.41)$ & $0.99(0.65-1.49)$ & $1.05(0.77-1.43)$ & $0.89(0.57-1.40)$ & $1.10(0.90-1.34)$ & $1.28(1.08-1.52)$ & $1.21(1.00-1.47)$ \\
\hline p-value & 0.239 & 0.948 & 0.752 & 0.613 & 0.360 & 0.005 & 0.050 \\
\hline Ever rhinitis symptoms & $1.01(0.84-1.23)$ & $1.03(0.70-1.52)$ & $0.98(0.74-1.30)$ & $1.23(0.84-1.79)$ & $1.06(0.89-1.26)$ & $1.36(1.18-1.58)$ & $1.31(1.11-1.54)$ \\
\hline p-value & 0.905 & 0.867 & 0.909 & 0.286 & 0.509 & $<0.001$ & 0.001 \\
\hline
\end{tabular}

Two-level logistic regression models (centre, individual), adjusted for age (baseline), sex (baseline), smoking (baseline), change of smoking habit from baseline to follow-up, body mass index (baseline) and education (follow-up). Bold type represents statistical significance. ${ }^{\#}$ : defined as water damage, floor dampness or visible mould in the past 12 months at baseline.

TABLE 5 Adjusted odds ratios with $95 \%$ confidence intervals for remission of respiratory symptoms and allergic rhinitis

\begin{tabular}{|c|c|c|c|c|c|c|c|}
\hline & Water damage & Floor dampness & Visible mould & Mould odour & Any dampness ${ }^{\#}$ & $\begin{array}{l}\text { Dampness or mould } \\
\text { at home during follow-up }\end{array}$ & $\begin{array}{l}\text { Dampness or mould } \\
\text { in the workplace building } \\
\text { during follow-up }\end{array}$ \\
\hline Wheeze & $0.89(0.70-1.15)$ & $1.01(0.68-1.49)$ & $1.21(0.88-1.67)$ & $1.02(0.69-1.53)$ & $0.93(0.75-1.16)$ & $0.87(0.71-1.06)$ & $0.71(0.57-0.89)$ \\
\hline$p$-value & 0.376 & 0.973 & 0.242 & 0.906 & 0.531 & 0.162 & 0.003 \\
\hline Nocturnal chest tightness & $0.70(0.51-0.97)$ & $0.69(0.42-1.14)$ & $0.64(0.42-0.96)$ & $0.71(0.42-1.20)$ & $0.68(0.51-0.92)$ & $0.84(0.64-1.12)$ & $0.76(0.56-1.02)$ \\
\hline p-value & 0.032 & 0.150 & 0.031 & 0.196 & 0.011 & 0.235 & 0.070 \\
\hline Nocturnal breathlessness & $0.63(0.39-1.02)$ & $0.55(0.27-1.09)$ & $0.52(0.29-0.95)$ & $0.70(0.35-1.42)$ & $0.59(0.38-0.91)$ & $0.83(0.54-1.27)$ & $0.68(0.43-1.09)$ \\
\hline p-value & 0.059 & 0.085 & 0.035 & 0.325 & 0.018 & 0.389 & 0.108 \\
\hline Nocturnal cough & $0.79(0.64-0.98)$ & $0.82(0.59-1.15)$ & $0.82(0.63-1.08)$ & $0.96(0.67-1.38)$ & $0.84(0.70-1.01)$ & $0.81(0.68-0.96)$ & $0.88(0.74-1.06)$ \\
\hline$p$-value & 0.030 & 0.257 & 0.163 & 0.828 & 0.057 & 0.013 & 0.194 \\
\hline Productive cough & $0.77(0.59-1.01)$ & $0.82(0.54-1.26)$ & $0.73(0.51-1.03)$ & $0.87(0.55-1.36)$ & $0.76(0.60-0.97)$ & $1.01(0.82-1.26)$ & $0.90(0.70-1.15)$ \\
\hline p-value & 0.055 & 0.368 & 0.077 & 0.541 & 0.026 & 0.909 & 0.387 \\
\hline Current asthma & $1.36(0.86-2.17)$ & $0.99(0.51-1.91)$ & $1.03(0.60-1.78)$ & $1.08(0.52-2.22)$ & $0.97(0.65-1.44)$ & $1.07(0.74-1.56)$ & $1.05(0.71-1.55)$ \\
\hline p-value & 0.192 & 0.970 & 0.912 & 0.843 & 0.885 & 0.705 & 0.816 \\
\hline Allergic rhinitis & $1.00(0.76-1.32)$ & $1.10(0.70-1.75)$ & $1.10(0.78-1.56)$ & $1.36(0.90-2.06)$ & $1.07(0.84-1.37)$ & $0.77(0.61-0.96)$ & $0.93(0.73-1.18)$ \\
\hline p-value & 0.991 & 0.676 & 0.576 & 0.148 & 0.581 & 0.021 & 0.535 \\
\hline
\end{tabular}

Two-level logistic regression models (centre, individual), adjusted for age (baseline), sex (baseline), smoking (baseline), change of smoking habit from baseline to follow-up, body mass index (baseline) and education (follow-up). Bold type represents statistical significance. ${ }^{\#}$ : defined as water damage, floor dampness or visible mould in the past 12 months at baseline. 


\begin{tabular}{|c|c|c|c|c|}
\hline & None & Only at home & Only at work & Both \\
\hline Wheeze & 1.00 & $1.34(1.09-1.65)$ & $1.45(1.14-1.84)$ & $1.75(1.34-2.28)$ \\
\hline p-value & & 0.005 & 0.003 & $<0.001$ \\
\hline Nocturnal chest tightness & 1.00 & $1.26(1.003-1.58)$ & $1.49(1.15-1.94)$ & $1.75(1.32-2.33)$ \\
\hline $\mathrm{p}$-value & & 0.047 & 0.003 & $<0.001$ \\
\hline $\begin{array}{l}\text { Nocturnal breathlessness } \\
\text { p-value }\end{array}$ & 1.00 & $\begin{array}{c}1.23(0.90-1.67) \\
0.191\end{array}$ & $\begin{array}{c}1.47(1.05-2.07) \\
\mathbf{0 . 0 2 6}\end{array}$ & $\begin{array}{c}1.54(1.04-2.28) \\
\mathbf{0 . 0 3 1}\end{array}$ \\
\hline $\begin{array}{l}\text { Nocturnal cough } \\
\text { p-value }\end{array}$ & 1.00 & $\begin{array}{c}1.16(0.97-1.38) \\
0.115\end{array}$ & $\begin{array}{c}1.44(1.18-1.76) \\
<0.001\end{array}$ & $\begin{array}{c}1.61(1.28-2.04) \\
<0.001\end{array}$ \\
\hline $\begin{array}{l}\text { Productive cough } \\
\text { p-value }\end{array}$ & 1.00 & $\begin{array}{c}1.51(1.23-1.85) \\
<0.001\end{array}$ & $\begin{array}{c}1.24(0.96-1.59) \\
0.096\end{array}$ & $\begin{array}{c}1.80(1.38-2.33) \\
<0.001\end{array}$ \\
\hline $\begin{array}{l}\text { Current asthma } \\
\text { p-value }\end{array}$ & 1.00 & $\begin{array}{c}1.11(0.83-1.48) \\
0.487\end{array}$ & $\begin{array}{c}1.42(1.04-1.94) \\
\mathbf{0 . 0 2 7}\end{array}$ & $\begin{array}{c}1.07(0.72-1.60) \\
0.741\end{array}$ \\
\hline $\begin{array}{l}\text { Doctor-diagnosed asthma } \\
\text { p-value }\end{array}$ & 1.00 & $\begin{array}{c}1.29(0.98-1.69) \\
0.068\end{array}$ & $\begin{array}{c}1.47(1.08-2.01) \\
\mathbf{0 . 0 1 6}\end{array}$ & $\begin{array}{c}1.51(1.06-2.15) \\
\mathbf{0 . 0 2 1}\end{array}$ \\
\hline $\begin{array}{l}\text { Allergic rhinitis } \\
\text { p-value }\end{array}$ & 1.00 & $\begin{array}{c}1.31(1.07-1.60) \\
\mathbf{0 . 0 1 0}\end{array}$ & $\begin{array}{c}1.29(1.01-1.65) \\
\mathbf{0 . 0 4 4}\end{array}$ & $\begin{array}{c}1.32(0.99-1.75) \\
0.055\end{array}$ \\
\hline $\begin{array}{l}\text { Ever rhinitis symptoms } \\
\text { p-value }\end{array}$ & 1.00 & $\begin{array}{c}1.28(1.07-1.52) \\
\mathbf{0 . 0 0 6}\end{array}$ & $\begin{array}{c}1.16(0.94-1.43) \\
0.167\end{array}$ & $\begin{array}{c}1.75(1.37-2.25) \\
<0.001\end{array}$ \\
\hline
\end{tabular}

Data are presented as adjusted OR $(95 \% \mathrm{CI})$, unless otherwise stated. Two-level logistic regression models (centre, individual), adjusted for age (baseline), sex (baseline), smoking (baseline), change of smoking habit from baseline to follow-up, body mass index (baseline) and education (follow-up). Bold type represents statistical significance.

in workplace buildings is associated with incidence of occupational asthma [29]. A population-based incident case-control study in Finland reported that visible mould and mould odour in the workplace were associated with adult-onset asthma $[6,14]$. Water damage was related to new-onset asthma among employees in two hospitals in the USA [15]. Higher level of fungal exposure in dust from a water-damaged office building was found to be associated with a higher prevalence of respiratory symptoms among the office workers in USA [30]. A prospective study from Sweden found that dampness and mould in the workplace building were associated with increased incidence and decreased remission of work-related symptoms [31].

Dampness at home and in the workplace building were related to onset of allergic rhinitis and rhinitis symptoms in our study. We have not found any other incident study on rhinitis among adults in relation to indoor dampness and mould. However, one prevalence study from China found that water damage at home was associated with current rhinitis, and visible indoor mould was associated with allergic rhinitis [27]. One Swedish population study found that mould odour was associated with pollen allergy (hay fever) [32]. Another Swedish study found that measured moisture load in the home, a marker of the excess water vapour, was associated with the prevalence of rhinitis [25].

\section{Strengths and limitations}

Initial selection bias is unlikely, since the participation rate for the initial ECRHS I postal questionnaire was high (86\%) [17], and the response rate from RHINE II to RHINE III was reasonable (71\%). Nonparticipants in RHINE II had slightly higher prevalence of respiratory symptoms, but lower prevalence of allergic rhinitis in ECRHS I. Nonparticipants in RHINE III $(n=4625)$ had slightly higher prevalence of respiratory symptoms and asthma in RHINE II as compared to participants. However, the prevalence of dampness indicators at baseline (RHINE II) did not differ between participants and non-respondents in RHINE III. Most of the exposure data were assessed at baseline to avoid recall bias. Similar results were obtained both in the crude and multivariate analysis with adjusting of potential confounders. Thus, our results are unlikely to be influenced by selection or information bias. One limitation is that we did not ask about family history of allergies or respiratory diseases.

\section{Conclusions}

Dampness and mould at home and in the workplace building can be risk factors for onset of respiratory symptoms, doctor-diagnosed asthma and rhinitis. Mould odour can be a risk factor for onset of respiratory symptoms and asthma. Dampness and indoor mould can decrease remission of respiratory symptoms and allergic rhinitis. There is a need to reduce indoor dampness and mould, as they may increase the risk of respiratory illnesses. 
Conflict of interest: None declared.

Support statement: The study was funded by the Icelandic Research Council, the Swedish Heart and Lung Foundation, the Vårdal Foundation for Health Care and Allergic Research, the Swedish Association Against Asthma and Allergy, the Swedish Council for Working Life and Social Research, the Swedish AFA Insurance (No. 467801100), the Bror Hjerpstedt Foundation, the Norwegian Research Council, the Norwegian Asthma and Allergy Association, the Danish Lung Association and the Estonian Science Foundation. Funding information for this article has been deposited with the Crossref Funder Registry.

\section{References}

1 Quansah R, Jaakkola MS, Hugg TT, et al. Residential dampness and molds and the risk of developing asthma: a systematic review and meta-analysis. PLoS One 2012; 7: e47526.

2 Jaakkola MS, Quansah R, Hugg TT, et al. Association of indoor dampness and molds with rhinitis risk: a systematic review and meta-analysis. J Allergy Clin Immunol 2013; 132: 1099-1110.

3 Fisk WJ, Eliseeva EA, Mendell MJ. Association of residential dampness and mold with respiratory tract infections and bronchitis: a meta-analysis. Environ Health 2010; 9: 72.

4 World Health Organization (WHO). WHO Guidelines for Indoor Air Quality: Dampness and Mould. Geneva, WHO, 2009.

5 Gunnbjörnsdóttir MI, Franklin KA, Norbäck D, et al. Prevalence and incidence of respiratory symptoms in relation to indoor dampness: the RHINE study. Thorax 2006; 61: 221-225.

6 Jaakkola MS, Nordman H, Piipari R, et al. Indoor dampness and molds and development of adult-onset asthma: a population-based incident case-control study. Environ Health Perspect 2002; 110: 543-547.

7 Norbäck D, Zock JP, Plana E, et al. Mould and dampness in dwelling places, and onset of asthma: the population-based cohort ECRHS. Occup Environ Med 2013; 70: 325-331.

8 Leynaert B, Bousquet J, Neukirch C, et al. Perennial rhinitis: an independent risk factor for asthma in nonatopic subjects: results from the European Community Respiratory Health Survey. J Allergy Clin Immunol 1999; 104: 301-304.

9 Shaaban R, Zureik M, Soussan D, et al. Rhinitis and onset of asthma: a longitudinal population-based study. Lancet 2008; 372: 1049-1057.

10 Eriksson J, Bjerg A, Lötvall J, et al. Rhinitis phenotypes correlate with different symptom presentation and risk factor patterns of asthma. Respir Med 2011; 105: 1611-1621.

11 Engvall K, Norrby C, Norbäck D. Asthma symptoms in relation to building dampness and odour in older multifamily houses in Stockholm. Int J Tuberc Lung Dis 2001; 5: 468-477.

12 Sun Y, Zhang Y, Bao L, et al. Ventilation and dampness in dorms and their associations with allergy among college students in China: a case-control study. Indoor Air 2011; 21: 277-283.

13 White SK, Cox-Ganser JM, Benaise LG, et al. Work-related peak flow and asthma symptoms in a damp building. Occup Med 2013; 63: 287-290.

14 Jaakkola MS, Jaakkola JJ. Office work exposures and adult-onset asthma. Environ Health Perspect 2007; 115: $1007-1011$.

15 Cox-Ganser JM, Rao CY, Park JH, et al. Asthma and respiratory symptoms in hospital workers related to dampness and biological contaminants. Indoor Air 2009; 19: 280-290.

16 Jarvis JQ, Morey PR. Allergic respiratory disease and fungal remediation in a building in a subtropical climate. Appl Occup Environ Hyg 2001; 16: 380-388.

17 Johannessen A, Verlato G, Benediktsdottir B, et al. Longterm follow-up in European respiratory health studies patterns and implications. BMC Pulm Med 2014; 14: 63.

18 Plaschke PP, Janson C, Norrman E, et al. Onset and remission of allergic rhinitis and asthma and the relationship with atopic sensitization and smoking. Am J Respir Crit Care Med 2000; 162: 920-924.

19 Haverinen-Shaughnessy U. Prevalence of dampness and mold in European housing stock. J Expo Sci Environ Epidemiol 2012; 22: 461-467.

20 Norbäck D, Zock JP, Plana E, et al. Building dampness and mold in European homes in relation to climate, building characteristics and socio-economic status: the European Community Respiratory Health Survey ECRHS II. Indoor Air 2017; 27: 921-932.

21 Lundholm M, Lavrell G, Mathiasson L. Self-leveling mortar as a possible cause of symptoms associated with "sick building syndrome". Arch Environ Health 1990; 45: 135-140.

22 Wieslander G, Norbäck D, Nordström K, et al. Nasal and ocular symptoms, tear film stability and biomarkers in nasal lavage, in relation to building-dampness and building design in hospitals. Int Arch Occup Environ Health 1999; 72: 451-461.

23 Norbäck D, Björnsson E, Janson C, et al. Current asthma and biochemical signs of inflammation in relation to building dampness in dwellings. Int J Tuberc Lung Dis 1999; 3: 368-376.

24 Wieslander G, Kumlin A, Norbäck D. Dampness and 2-ethyl-1-hexanol in floor construction of rehabilitation center: health effects in staff. Arch Environ Occup Health 2010; 65: 3-11.

25 Wang J, Engvall K, Smedje G, et al. Current wheeze, asthma, respiratory infections, and rhinitis among adults in relation to inspection data and indoor measurements in single-family houses in Sweden - the BETSI study. Indoor Air 2017; 27: 725-736.

26 Norbäck D, Wieslander G, Nordström K, et al. Asthma symptoms in relation to measured building dampness in upper concrete floor construction, and 2-ethyl-1-hexanol in indoor air. Int J Tuberc Lung Dis 2000; 4: 1016-1025.

27 Wang J, Li B, Yu W, et al. Rhinitis symptoms and asthma among parents of preschool children in relation to the home environment in Chongqing, China. PLoS One 2014; 9: e94731.

28 Norbaäck D, Nordström K. An experimental study on effects of increased ventilation flow on students' perception of indoor environment in computer classrooms. Indoor Air 2008; 18: 293-300.

29 Caillaud D, Leynaert B, Keirsbulck M, et al. Indoor mould exposure, asthma and rhinitis: findings from systematic reviews and recent longitudinal studies. Eur Respir Rev 2018; 27: 170137.

30 Park JH, Cox-Ganser J, Rao C, et al. Fungal and endotoxin measurements in dust associated with respiratory symptoms in a water-damaged office building. Indoor Air 2006; 16: 192-203. 
31 Zhang X, Sahlberg B, Wieslander G, et al. Dampness and moulds in workplace buildings: associations with incidence and remission of sick building syndrome (SBS) and biomarkers of inflammation in a 10 year follow-up study. Sci Total Environ 2012; 430: 75-81.

32 Norbäck D, Lampa E, Engvall K. Asthma, allergy and eczema among adults in multifamily houses in Stockholm (3-HE study) - associations with building characteristics, home environment and energy use for heating. PLoS One 2014; 9: e112960. 